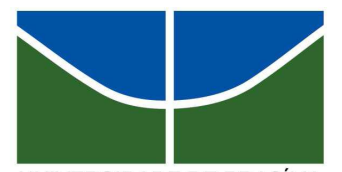

UNIVERSIDADE DE BRASÍLIA

Centro de Excelência em Turismo

Pós Graduação Lato Sensu

Curso de Especialização em Gastronomia e Saúde

\title{
PIMENTAS: TIPOS, UTILIZAÇÃO NA CULINÁRIA E FUNÇÕES NO ORGANISMO
}

\author{
Raquel Daneliczen Zancanaro
}

Orientador: Prof. Dr ${ }^{\mathrm{a}}$. Raquel Botelho 


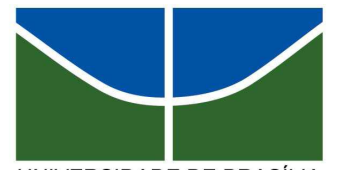

UNIVERSIDADE DE BRASÍLIA

Centro de Excelência em Turismo

Pós Graduação Lato Sensu

Curso de Especialização em Gastronomia e Saúde

\title{
PIMENTAS: TIPOS, UTILIZAÇÃO NA CULINÁRIA E FUNÇÕES NO ORGANISMO
}

\author{
Raquel Daneliczen Zancanaro
}

Orientador: Prof. Dra . Raquel Botelho

Monografia apresentada ao Centro de Excelência em Turismo - CET, da Universidade de Brasília - UnB, como requisito parcial à obtenção do grau de Especialista em Gastronomia e Saúde

Brasília - 2008 


\section{UNIVERSIDADE DE BRASÍLIA}

Centro de Excelência em Turismo

Pós Graduação Lato Sensu

Curso de Especialização em Gastronomia e Saúde

Monografia apresentada ao Centro de Excelência em Turismo - CET, da Universidade de Brasília - UnB, como requisito parcial à obtenção do grau de Especialista em Gastronomia e Saúde.

\section{PIMENTAS: TIPOS, UTILIZAÇÃO NA CULINÁRIA E FUNÇÕES NO ORGANISMO}

Raquel Daneliczen Zancanaro

Aprovado por:

Prof. Dr. Raquel Botelho

Prof. Msc. Fabiana Queiroz

Prof. Msc. Renata Zandonadi

Brasília, 22 de julho de 2008 
DEDICATÓRIA

Dedico esse trabalho aos meus pais, por terem me proporcionado mais essa oportunidade de aprendizado e ao meu noivo pelo carinho e compreensão. 
AGRADECIMENTO

Agradeço primeiramente a Deus pela sabedoria. Aos amigos pela amizade e a minha orientadora Raquel Botelho pelos ensinamentos. 
"É melhor tentar e falhar, que preocupar-se e ver a vida passar. É melhor tentar, ainda em vão, que sentar-se fazendo nada até o final. Eu prefiro na chuva caminhar que em dias triste em casa me esconder. Prefiro ser feliz, embora louco, que em conformidade viver..."

Martin Luther King 


\section{RESUMO}

Usadas mundialmente, inclusive pelos povos antigos, as pimentas tornaram-se símbolo da culinária, consideradas uma das mais importantes especiarias, utilizadas na preparação de diversos pratos conferindo sabor e picância de acordo com a pimenta utilizada. Estudos mostram que além de realçar o sabor dos alimentos, também têm várias funções benéficas à saúde. O valor nutricional é relativamente alto, por constituirem boas fontes de vitaminas, principalmente $\mathrm{C}$ e $\mathrm{A}$ e por apresentarem ainda vários minerais que são fundamentais para o perfeito funcionamento do organismo. As espécies mais consumidas no Brasil pertencem aos gêneros: Capsicum baccatum e Capsicum chinense, isso varia conforme a região, bem como os nomes que elas podem assumir. As pimentas hoje, são cultivadas de Norte a Sul do Brasil e são muito importantes para economia do país e para o regionalismo.

Palavras-chave: Capsaicina, Capsicum, pimenta, saúde 


\begin{abstract}
Used worldwide, including the old people, the peppers have become the symbol of cooking, as one of the most important spices, used in the preparation of various dishes with flavor and piquancy according to the pepper used. Studies show that also highlights the flavor of foods, they also have several functions beneficial to health. The nutritional value is relatively high, for as good sources of vitamins, especially $\mathrm{A}$ and $\mathrm{C}$ and to have even more minerals which are essential for the perfect functioning of the body. The species most consumed in Brazil belong to the genera: Capsicum baccatum and Capsicum chinense, this varies according to region, and the names they can take. The peppers today, are grown from North to South and Brazil are very important for the country's economy and for regionalism..
\end{abstract}

Keywords: Capsaicina, Capsicum, pepper, health 


\section{LISTA DE ILUSTRAÇÕES}

Figura 1. Foto de jalapeno ainda sem colher $\quad 19$

Figura 2. Foto de mulata ainda sem colher $\quad 19$

Figura 3. Foto de pimenta-de-mesa ainda sem colher 20

Figura 4. Foto de pimentões 20

$\begin{array}{ll}\text { Figura 5. Foto de piquin ainda sem colher } & 21\end{array}$

$\begin{array}{ll}\text { Figura 6. Foto de Cambuci ainda sem colher } & 21\end{array}$

Figura 7. Foto de cumari verdadeira ainda sem colher 22

Figura 8. Foto de dedo-de-moça ainda sem colher 23

Figura 9. Foto de peito-de-moça ainda sem colher 23

Figura 10. Foto de pimenta fina ainda sem colher 24

Figura 11. Foto de pitanga ainda sem colher $\quad 24$

Figura 12. Foto de cabacinha ainda sem colher 25

Figura 13. Foto de chora-menino ainda sem colher 25

Figura 14. Foto de cumari-do-pará ainda sem colher 26

Figura 15. Foto de murupi ainda sem colher 26

Figura 16. Foto de pimenta biquinho ainda sem colher 27

Figura 17. Foto de pimenta-de-bode ainda sem colher 27

Figura 18. Foto de pimenta-de-cheiro ainda sem colher 28

Figura 19. Foto de pimenta-de-cheiro-do-Norte ainda sem colher 28

Figura 20. Foto de malagueta ainda sem colher 29

Figura 21. Foto de pimenta-de-passarinho ainda sem colher 30

Figura 22. Foto de tabasco ainda sem colher 30

Figura 23. Foto de cubeba antes de moer $\quad 31$

Figura 24. Foto de pimenta-do-reino branca em grãos 31

Figura 25. Foto de pimenta-do-reino preta em grãos 32

Figura 26. Foto de pimenta-do-reino rosa ainda sem colher 32

Figura 27. Foto de pimenta-do-reino verde ainda sem colher 33

Figura 28. Foto de Jamaica em grãos 33

Figura 29. Foto de pimenta-de-macaco ainda sem colher 34

Figura 30. Foto de pimenta rosa ainda sem colher 34

Figura 31. Foto de pimenta síria 35

Figura 32. Foto de pimenta-da-tasmânia em grãos 35 
Figura 33. Quadro resumo do grau de ardência e utilização na culinária das 36 pimentas 


\section{SUMÁRIO}

1. INTRODUÇÃO 12

2. OBJETIVOS 14

3. METODOLOGIA 15

4. REVISÃO DE LITERATURA 16

$\begin{array}{ll}4.1 \text { Origem das pimentas } & 16\end{array}$

4.2 Grau de ardência 17

4.3 Tipos de pimentas cultivadas no Brasil e seu uso na culinária 18

4.3.1 Capsicum annuum 18

$\begin{array}{ll}\text { 4.3.2 Capsicum baccatum } & 21\end{array}$

4.3.3 Capsicum chinense $\quad 24$

4.3.4 Capsicum frutescens 28

4.3.5 Piperaceas 30

4.3.6 Falsas Pimentas 33

4.4 Composição das pimentas 37

$\begin{array}{ll}4.5 \text { Os benefícios para saúde } & 38\end{array}$

5. CONCLUSÃO 41

6. REFERÊNCIAS BIBLIOGRÁFICAS 42 


\section{INTRODUÇÃO}

As pimentas são plantas utilizadas na alimentação que produzem as sensações picante e de calor devido aos seus componentes químicos, capazes de estimular as papilas gustativas da boca. Basicamente há dois gêneros de pimentas mais conhecidos, o Piper e o Capsicum (BONTEMPO, 2007).

As mais antigas são do gênero Piper, que são sementes de plantas da família das piperáceas. O principio ativo mais importante deste gênero é a piperina (BONTEMPO, 2007).

O gênero Capsicum compreende cerca de 30 espécies conhecidas. As pimentas do gênero Capsicum pertencem à família das solanáceas, da qual fazem parte a berinjela e a batata. $\mathrm{O}$ principio ativo mais importante desse gênero é a capsaicina (BONTEMPO, 2007).

No Brasil são feitos diferentes usos das pimentas e para cada um existe um tipo de preparo ou procedimento. As pimentas podem ser saboreadas frescas puras, desidratadas (que podem ser secas ao sol ou por outras técnicas, duram mais, ardem menos) e frescas em molhos (SILVA, 1996).

As pimentas também podem ser harmonizadas com os pratos, só que os termos de comparação são diferentes, o que deve ser considerado é: o teor de ardência ou picância, isto é o fator de calor que ela provoca no sabor, os ingredientes do seu molho ou do seu extrato (ORRICO, 2004).

Algumas pesquisas sobre as cozinhas brasileiras mostram que as pimentas combinam, de acordo com as suas características e com as características do que está sendo servido, e competem, sobrepujam ou são inadequadas a outros. Não são regras absolutas nem extremamente rígidas, porque pimenta também tem gosto subjetivo, hábito cultural e até de tabu religioso (ORRICO, 2004).

As pimentas foram possivelmente os primeiros aditivos alimentares utilizados pelas civilizações antigas do México e da América do Sul. Essas civilizações conheciam a contribuição daqueles frutos para o aroma, cor e sabor dos alimentos, e assim selecionaram variedades para usos específicos. As pimentas eram usadas regularmente para tornar a ingestão de carnes e cereais mais atraente. Possuíam também a função de preservar os alimentos da contaminação por bactérias e fungos patogênicos, contribuindo para a saúde e longevidade e a manutenção da capacidade reprodutiva daquela gente (REIFSCHNEIDER, 2000). 
As pimentas são estimulantes do apetite e auxiliares da digestão. Sua ingestão aumenta a salivação e estimula a secreção gástrica e a motilidade gastrintestinal, promovendo a sensação de bem estar após a ingestão (BONTEMPO, 2007).

Os nutrientes quando em proporções adequadas na dieta são capazes de assegurar a manutenção das funções vitais do organismo, suprindo as suas necessidades de produção de energia, de elaboração e manutenção tecidual e de equilíbrio biológico. Todos esses componentes são encontrados nos frutos de Capsicum em quantidades variáveis (REIFSCHNEIDER, 2000).

Por todas essas propriedades, será demonstrada por revisão bibliográfica os diferentes tipos de pimentas e suas características para utilização pelo homem. Da origem a caracterização, explorar-se-á os benefícios para a saúde e a utilização na culinária regional. 


\section{OBJETIVOS}

OBJETIVO GERAL:

Demonstrar os tipos de pimenta e seus benefícios à saúde.

\section{OBJETIVOS ESPECÍFICOS:}

- Descrever o histórico das pimentas,

- Identificar os tipos de pimentas,

- Verificar o uso na culinária regional,

- Descrever suas funções e benefícios para saúde. 


\section{METODOLOGIA}

Foi realizada uma pesquisa exploratória com o intuito de proporcionar maior conhecimento sobre as pimentas (origem, tipos, funções e usos). Nesta pesquisa foram utilizados livros e artigos científicos das bases de dados da Capes que retratam o assunto. Foram utilizadas como palavras chave: Capsaicina, Piperina, Pimenta, Capsicum, Saúde. A pesquisa foi realizada nas línguas espanhola, inglesa e portuguesa.

O trabalho foi dividido em: origem das pimentas, tipos e utilização das pimentas na culinária nacional e regional, onde são mais cultivadas no Brasil, composição das pimentas e os benefícios que estas trazem a saúde. 


\section{REVISÃO BIBLIOGRÁFICA}

\subsection{Origem da pimenta}

O nome pimenta vem da forma latina pigmentum, "matéria corante", que no espanhol virou pimienta, passando depois ao entendimento contemporâneo de "especiaria aromática" (BONTEMPO, 2007).

Registros arqueológicos indicam que a pimenta já era utilizada nove mil anos atrás no México e 2.500 anos antes de Cristo no Peru. Hipócrates, célebre médico e filósofo da Grécia Antiga, encontrava na pimenta um poderoso princípio curativo (NETO, 2004).

$\mathrm{Na}$ história brasileira a pimenta marca a sua participação desde o descobrimento. Colombo, Cabral e outros navegantes da Coroa já haviam recolhido nas Índias inúmeras especiarias para levar à corte portuguesa, de onde eram comercializadas para toda a Europa: cravos, paus de canela, pimentas-do-reino, noz-moscada, gengibre, açafrão, pimentas, etc (NETO, 2004).

A pimenta-do-reino, pimenta-preta ou pimenta da Índia (cujo nome científico é Piper nigrum) monopolizava o mercado das pimentas, era tão apreciada e valorizada, principalmente pelo seu efeito conservante sobre a carne, que chegou a ser aceita como moeda, dando origem inclusive à locução "pagar em espécie” (GARCIA, 2000).

Portanto, a busca pelas novas terras era movida também pelo desejo e até necessidade da obtenção de ervas, temperos, cosméticos e essências para cozinhar, tratar doenças, embelezar, produzir riquezas, conservar produtos. Tanto que, das Américas, de onde é oriunda a maioria das espécies, as pimentas se disseminaram por todo o continente europeu e passaram a ser cultivadas até nas colônias africanas e asiáticas (ORRICO, 2004).

Os índios brasileiros já cultivavam e empregavam largamente as pimentas na sua alimentação frescas ou secas, temperando os peixes e as caças cruas, acompanhando as comidas e como arma de defesa contra os invasores. Os africanos reforçaram esse hábito, trouxeram algumas espécies para o Brasil e também proporcionaram aos portugueses a descoberta de tão saborosos e inusitados aromas, cheiros e temperos nas comidas, pois em geral eram as negras as responsáveis pelo repasto dos brancos (STADEN, 1974).

Atualmente, contam-se mais de 150 variedades de Capsicum catalogadas no mundo, todas derivadas de apenas cinco espécies consideradas domesticadas. Há também as espécies silvestres (aproximadamente 40) as quais, eventualmente são usadas em cruzamentos para 
tornar os cultivos comerciais mais resistentes a doenças e pragas. Existem também inúmeras outras variedades que ainda não foram descobertas, especialmente na Mata Atlântica brasileira. Tamanha diversidade entre as Capsicum é propiciada pela facilidade com que ocorrem cruzamentos entre os exemplares de uma mesma espécie e até de espécies diferentes. Quando esses cruzamentos acontecem, apenas a primeira geração é de sementes híbridas, ou seja, incapazes de se reproduzir. Depois, novos cruzamentos vão sendo estabelecidos, num processo lento e que tem nos insetos, principalmente nas abelhas melíferas, seu principal agente de diversificação. Além disso, as Capsicum pertencem a uma espécie de reprodução genética autógama (em que as flores são hermafroditas e se autofecundam) (NETO, 2004).

A domesticação de uma espécie se dá quando o homem interfere nesse processo de seleção natural. Nesse caso, ele define de acordo com seus interesses de cultivo, produtividade e qualidade, quais são as características que deseja perpetuar. E assim passa a selecionar as sementes apenas das plantas em que essas características ocorrem de forma mais nítida. Atualmente as variedades cultivadas que entram na categoria de espécies domesticadas são: Capsicum annum, Capsicum chinense e Capsicum pubescens (REIFSCHNEIDER, 2000).

A classificação de uma pimenta em um ou outro grupo se dá pela análise de grau de pungência, coloração, tamanho e formato dos frutos, além do porte da planta (REIFSCHNEIDER, 2000).

No Brasil as pimentas são cultivadas igualmente nas regiões de clima quente e frio. E, nos últimos dez anos, vêm se firmando como item de grande importância tanto na culinária quanto no comércio nacional. Com seu vasto território, o Brasil oferece inúmeros espaços propícios ao plantio de pimentas diversas. Por isso, grandes empresas multinacionais já estão se dedicando a esse tipo de cultivo e promovendo a exportação das pimentas brasileiras para os Estados Unidos, a Alemanha, a China, o Japão e vários outros países (NETO, 2004).

\subsection{Grau de ardência}

Em 1912, o farmacologista Wilbur L. Scoville desenvolveu um teste para determinar, com o máximo de precisão o grau de pungência de cada variedade de Capsicum (REIFSCHNEIDER, 2000).

Nesse teste, organoléptico, cinco pessoas analisam a solução obtida a partir de um peso exato de pimentas dissolvidas em álcool e diluídas em água e açúcar. 
Quanto maior a picância da amostra, maior a necessidade de diluição, até que a picância deixe de ser sentida pelo paladar. Assim, se uma diluição necessita de 1000 unidades de água para uma unidade de solução em álcool, a amostra indica uma picância de 1000 unidades de Scoville. Apesar de ser muito subjetivo, até hoje esse teste permanece como um dos mais bem aceitos mecanismos para determinar a ardência das pimentas (BONTEMPO, 2007).

Existe também outra escala para determinar a ardência das pimentas. Denominada de escala de temperatura, ela foi criada por Julie Cohn. Nessa escala, as pimentas têm sua picância subjetivamente classificada como de 1 a 10. Os graus 8, 9 e 10 são reservados as espécies muito picantes; 4, 5 e 6 atribuem-se as pimentas de média ardência; e 1, 2 e 3 designam as variedades mais suaves (NETO, 2004).

\subsection{Tipos de pimentas cultivadas no Brasil e seu uso na culinária}

\subsubsection{Capsicum annuum}

Engloba as principais variedades de Capsicum atualmente conhecidas e cultivadas no mundo inteiro. Tanto os pimentões quanto a maioria das pimentas ornamentais fazem parte da família. E, ao contrário do que indica o nome annuиm (que significa anual), suas plantas têm ciclos de colheita perenes. As flores são bastante semelhantes entre si, mas os frutos apresentam grande diversidade de cores, tamanhos e formatos (REIFSCHNEIDER, 2000).

Os botânicos acreditam que, originalmente, as plantas desta família ocupavam os territórios que hoje correspondem à Bolívia, ao México e ao Sudeste brasileiro. Ainda em sua forma silvestre, elas teriam se espalhado por toda a América do Sul e Central, subindo até a divisa do México e Estados Unidos. Milhares de anos mais tarde, descobertas pelos exploradores europeus e transportadas para diferentes países, foram domesticadas para cultivo (NETO, 2004).

\section{Jalapeno}

Ao lado do tabasco, é a pimenta mais popular da América do Norte e, no Brasil, é produzida nos estados de São Paulo, Minas Gerais e Goiás. Sua polpa garante-lhe o lugar de melhor pimenta para a elaboração de molhos. Os frutos, de paredes espessas, possuem formato cônico, com cerca de 5 a $8 \mathrm{~cm}$ de comprimento e 2,5 a $3 \mathrm{~cm}$ de largura. Antes de amadurecerem apresentam a coloração verde, estriada de tons que variam de claro a escuro 
(Figura 1), tornando-se vermelhos depois de maduros (o mais comum é que seja consumida ainda verde). De pungência média e aroma acentuado, pode ser consumida fresca ou processada na forma de molhos, conservas e desidratadas. Quando seca e defumada recebe o nome de "chipotle". Sua picância chega a 5 na escala de temperatura e oscila entre 2,5 mil e 5 mil unidades Scoville (REIFSCHNEIDER, 2000; NETO, 2004).

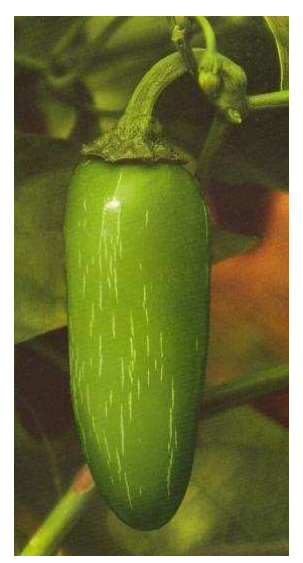

Figura 1. Foto de jalapeno ainda sem colher

\section{Mulata}

Conhecida também como sweet purple pepper, devido a sua cor roxa, produz efeitos decorativos nos pratos (Figura 2). Mede em torno de $2,5 \mathrm{~cm}$ de diâmetro e $5,5 \mathrm{~cm}$ de comprimento. Com sabor semelhante ao do pimentão, deve ser usada em saladas, crua ou grelhada. Apresenta baixa picância, entre 100 e 500 unidades Scoville e de 0 a 1 na escala de temperatura. É cultivada principalmente na Holanda e no Brasil, onde a produção concentrase no interior de São Paulo (BONTEMPO, 2007; NETO, 2004).

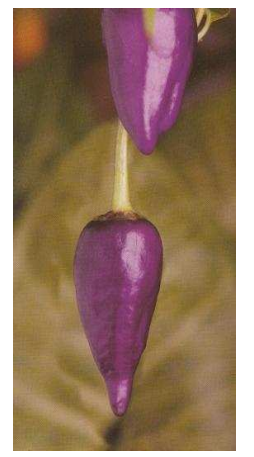

Figura 2. Foto de mulata ainda sem colher

\section{Pimenta-de-mesa}

Seus frutos pequenos e eretos (Figura 3) têm forma triangular e apresentam coloração verde ou roxa antes de amadurecerem. Depois, tornam-se vermelhos. As flores geralmente são 
brancas, violetas ou roxas. De picância baixa, atinge 2 mil unidades Scoville e 3,5 pontos na escala de temperatura. É muito conhecida na região Oeste do estado de São Paulo, e largamente empregada em carnes, molhos e saladas (IBURG, 2005).

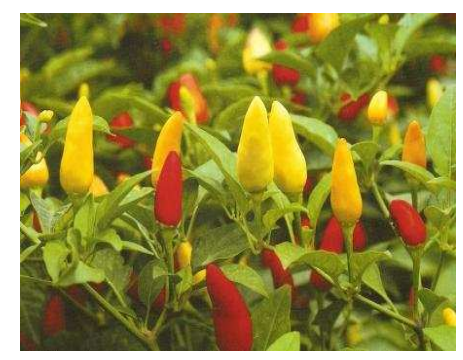

Figura 3. Foto de Pimenta-de-mesa ainda sem colher

\section{Pimentão}

Chamado de Bell pepper no idioma inglês e difundido no mundo inteiro, o pimentão (Figura 4) está entre as dez hortaliças mais importantes do mercado brasileiro e tem presença marcante também na Hungria e na Espanha. Seus frutos têm formatos variados, lembrando quadrados, retângulos e, mais comumente, cones. Também tem a coloração diversificada, vai do verde, passa para o amarelo e adquire na fase de maturação as cores vermelho, roxo e marrom escuro. Seu índice de picância é zero, tornando-o ideal para o consumo em saladas, refogados, grelhados e recheados. Também é empregado em molho champanha, escabeches e patês. Na forma industrializada, é vendido desidratado (em flocos ou em pó), sem pele e curtido no azeite grelhado. A páprica doce nada mais é do que pimentão desidratado e moído (REIFSCHNEIDER, 2000; IBURG, 2005).

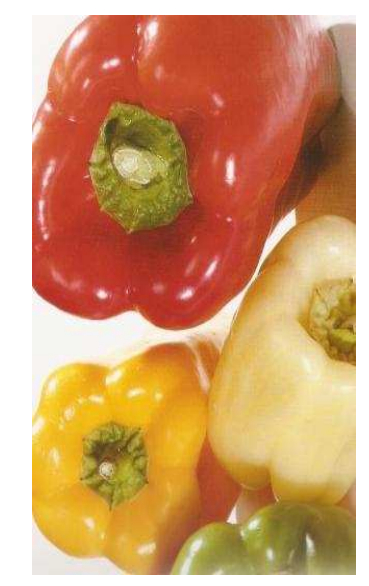

Figura 4. Foto de pimentões

\section{Piquin}

$\mathrm{Na}$ forma silvestre é chamada popularmente como pimenta-mosquito, pimentapassarinho e pimenta-brava. De alta pungência registra entre 40 mil e 70 mil unidades 
Scoville, e 8 a 9 na escala de temperatura, imprime intensa picância aos pratos. Na natureza, seus frutos medem 0,6 a $1,3 \mathrm{~cm}$ tanto de comprimento quanto de largura, embora o fruto cultivado possa atingir até $3 \mathrm{~cm}$ de comprimento (Figura 5). É considerada a melhor pimenta para sopas, lentilhas, feijão e ervilhas. Seus frutos verdes são comumente usados também no preparo de escabeches (NETO, 2004).

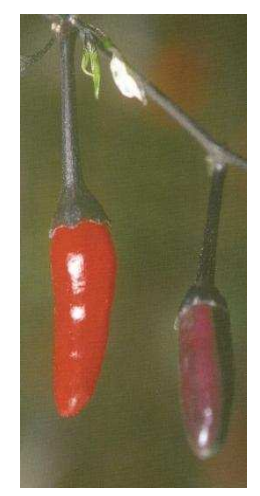

Figura 5. Foto de piquin ainda sem colher

\subsubsection{Capsicum baccatum}

O termo baccatum significa semelhante a uma baga que corresponde ao formato dos pequenos frutos dessa família de pimentas, as quais, nos países de língua espanhola da América Latina, são chamadas de aji. Originárias da América do Sul, mais especificamente da Bolívia e do Peru, as variedades dessa espécie tem pungência suave e hoje são cultivadas também na Argentina, Colômbia, Equador e Brasil. Mesmo domesticadas, elas ainda apresentam ampla diversidade quanto às formas $\mathrm{e}$ aos tamanhos das suas bagas (REIFSCHNEIDER, 2000; NETO, 2004).

\section{Cambuci}

Fácil de identificar, essa pimenta tem frutos de tamanho mediano, com cerca de $4 \mathrm{~cm}$ de comprimento e $7 \mathrm{~cm}$ de largura. Devido à forma de campânula (Figura 6) é chamada também de chapéu-de-frade. Sua cor amarela-alaranjada torna-a bastante atrativa. Sem pungência alguma é considerada de sabor adocicado pelos apreciadores de pimentas. Pode ser consumida fresca, em saladas, cozidos ou conservas (IBURG, 2005). 


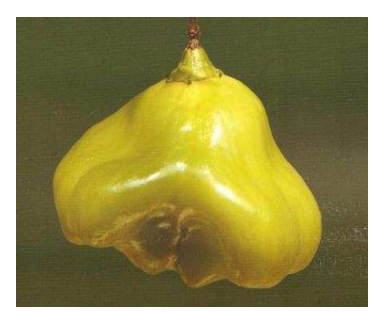

Figura 6. Foto de cambuci ainda sem colher

\section{Cumari verdadeira}

Conhecida também pelos nomes de cumbari e comari, é encontrada apenas no Brasil, onde seu consumo vem crescendo ano a ano. É bastante popular no Sudeste brasileiro, onde a colhem ainda verde (Figura 7), em tempo de evitar que os pássaros comam seus frutos, de forma redonda ou ovalada. Embora ainda seja tida como uma variedade silvestre, uma demanda crescente pelo seu consumo vem motivando algumas plantações experimentais, que brevemente podem dar origem a cultivos extensivos. Bastante empregada em molhos, cozidos e marinados, tem picância média entre 30 mil e 50 mil unidades Scoville e 8 na escala de temperatura (BONTEMPO, 2007; NETO, 2004).

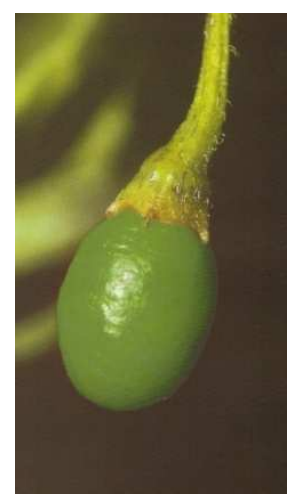

Figura 7. Foto de cumari verdadeira ainda sem colher

\section{Dedo-de-moça}

É uma das pimentas mais consumidas no Brasil, principalmente nas regiões Sul e Sudeste do país, onde também recebe os nomes de chifre-de-veado e de pimenta vermelha. Quando seca e picada é conhecida ainda como pimenta calabresa. Na natureza, seus frutos alongados e vermelhos (Figura 8), medem entre 6,5 e $8 \mathrm{~cm}$ e têm de 1 a 1,5 cm de largura. Sua picância que varia de suave a mediana, torna-a adequada para o tempero de azeitonas e de molhos em geral. Consumida também em saladas e cozidos, pose ser adicionada ao feijão ou servir de acompanhamento a diversos aperitivos. Na escala Scoville sua pungência oscila de 5 mil a 15 mil unidades, com variação de 5 a 6 na escala de temperatura (IBURG, 2005; NETO, 2004). 


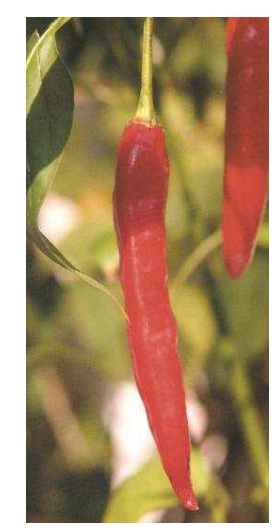

Figura 8. Foto de dedo-de-moça ainda sem colher

\section{Peito-de-moça}

Bastante popular na região Centro-Oeste do Brasil, essa pimenta apresenta forma triangular (Figura 9) e mede cerca de 3,5 cm com largura de 2,5 cm. Quando madura adquire coloração vermelha brilhante. De picância mediana, atinge 10 mil unidades Scoville e de 5 a 6 na escala de temperatura. Pode ser consumida em saladas, molhos, cozidos e no feijão. Devido ao seu belo formato, é muito usada para decorar diferentes pratos (BONTEMPO, 2007).

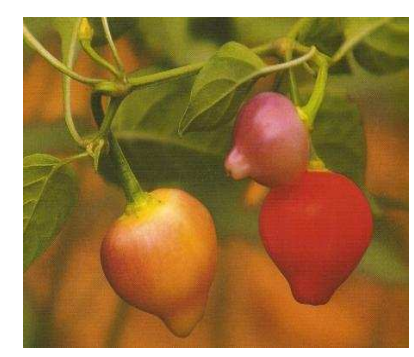

Figura 9. Foto de peito-de-moça ainda sem colher

\section{Pimenta fina}

Seus frutos são alongados e apresentam uma leve protuberância na parte inferior (Figura 10). Lembram bastante a pimenta dedo-de-moça, mas com tamanho menor e sabor mais picante. Consumida preferencialmente madura, quando atinge a cor vermelha, apresenta alta pungência, entre 30 mil a 50 mil unidades na escala Scoville e 8 na escala de temperatura. Pode ser empregada em saladas, cozidos e como tempero de feijão (NETO, 2004). 


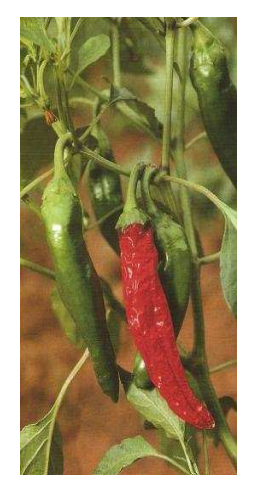

Figura 10. Foto de pimenta fina ainda sem colher

\section{Pitanga}

De frutos arredondados, cor vermelha e estrias laterais, lembrando a fruta pitanga (Figura 11). Apesar de bastante conhecida no Centro-Oeste brasileiro, ainda é pouco consumida. Mede entre 2 e $3 \mathrm{~cm}$ de diâmetro e atinge até $2 \mathrm{~cm}$ de comprimento. Pode ser utilizada em caldos e ensopados de peixe. Sua picância fica entre 15 mil e 30 mil unidades Scoville, variando de 5 a 6 na escala de temperatura (IBURG, 2005; NETO, 2004).

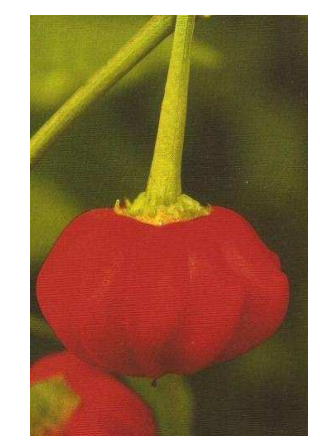

Figura 11. Foto de pitanga ainda sem colher

\subsubsection{Capsicum chinense}

Apesar do nome que significa originária da China, esta espécie é típica da Bacia Amazônica. Elas são menos conhecidas do que as pimentas annuum. A família Capsicum chinense é dotada de uma multiplicidade de formatos e cores de frutos, apresenta mais de 40 variedades. O grau de picância dos seus frutos varia da mais suave até a mais forte, podendo atingir 500 mil unidades Scoville (REIFSCHNEIDER, 2000).

\section{Cabacinha}

Muito conhecida em algumas regiões do Brasil, especialmente no interior de São Paulo e no Sul de Minas Gerais, essa pimenta, que alguns chamam de fidalga, adquire uma cor alaranjada quando está madura (Figura 12). Apresenta formato campanulado, com $4 \mathrm{~cm}$ 
de comprimento e cerca de 1,5 a 2,5 de largura. Picante, atinge 50 mil unidades Scoville e 8 pontos na escala de temperatura. É muito utilizada em molho e saladas. Também é bastante apreciada na decoração de pratos (NETO, 2004; BONTEMPO, 2007).

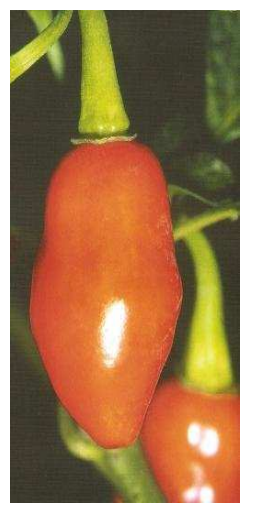

Figura 12. Foto de cabacinha ainda sem colher

\section{Chora-menino}

Seu fruto é arredondado e de cor amarela (Figura 13), mede entre 3 e $4 \mathrm{~cm}$ de diâmetro e atinge até $5 \mathrm{~cm}$ de comprimento. Sua picância apresenta uma característica curiosa, é imperceptível em um primeiro momento, mas alguns minutos após a degustação manifesta um forte ardor. Mais conhecida na região Nordeste do Brasil, especialmente na Bahia, costuma ser usada em saladas, peixes, caldos e sopas. Sua pungência situa-se entre 30 mil e 50 mil unidades Scoville e 7 a 8 na escala de temperatura (IBURG, 2005).

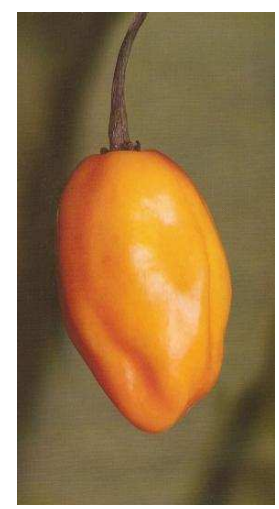

Figura 13. Foto de chora-menino ainda sem colher

\section{Cumari-do-Pará}

Também conhecida como cumari-amarela e pimenta-de-cheiro, costuma ser confundida com cumari verdadeira. Com frutos triangulares (Figura 14), que medem $3 \mathrm{~cm}$ de comprimento por $1 \mathrm{~cm}$ de largura, torna-se amarela ao amadurecer. Aromática e muito picante 
apresenta um grau de pungência em torno de 50 mil unidades Scoville e 8 na escala de temperatura. É bastante utilizada em conservas (IBURG, 2005; NETO, 2004).

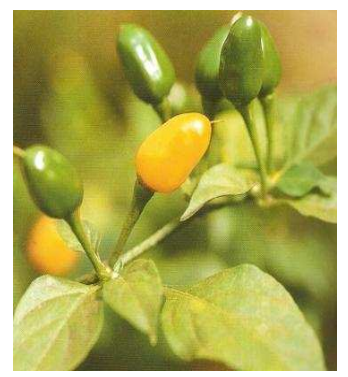

Figura 14. Foto de cumari-do-pará ainda sem colher

\section{Murupi}

Tradicionalmente cultivada na região Norte do Brasil, tem aroma característico e sabor picante. Pode ser encontrada fresca, na forma de molhos, ou ainda em conservas à base de vinagre, óleo e soro de leite. Seus frutos são alongados (Figura 15) e antes de amadurecerem apresentam coloração verde. Depois adquirem um tom amarelo que se intensifica até o vermelho, quando as pimentas estão maduras. $\mathrm{O}$ comprimento varia, as menores que medem de 2 a $4 \mathrm{~cm}$, têm pungência mais acentuada e são conhecidas como murupizinho. Os frutos de tamanho intermediário apresentam de 3,5 a $6 \mathrm{~cm}$ de comprimento e são chamadas de murupi comum. Há também o murupi grande, com $9 \mathrm{~cm}$ de comprimento. Trata-se de uma variedade de alta picância, atingindo 60 mil unidades Scolville e entre 8 e 9 pontos na escala de temperatura (NETO, 2004).

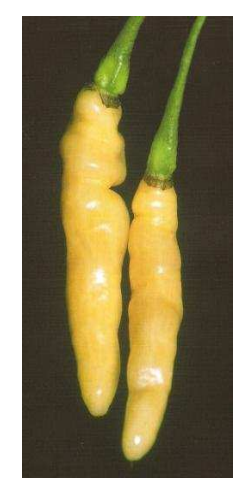

Figura 15. Foto de murupi ainda sem colher

\section{Pimenta de biquinho}

Recebe este nome porque seu fruto arredondado estreita-se completamente na ponta, ganhando um formato parecido com a de um bico (Figura 16). De cor vermelha forte, ela mede $3 \mathrm{~cm}$ de comprimento e alcança 1,5 de largura. É uma variedade que esta se difundindo com grande rapidez no estado de Minas Gerais, onde sempre foi usada como planta 
ornamental e agora vem sendo empregada no preparo de molho, peixes e carnes. Também é muito apreciada em conservas feitas em garrafas de aguardente. Sua picância, considerada fraca, é de 1000 unidades Scoville e de 1 ponto na escala de temperatura (BONTEMPO, 2007).

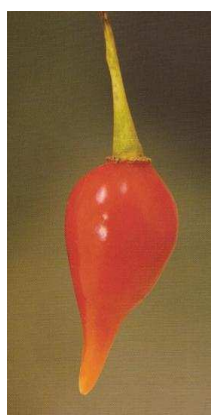

Figura 16. Foto de pimenta biquinho ainda sem colher

\section{Pimenta-de-bode}

Muito popular na região Sudeste do Brasil, essa variedade apresenta frutos redondos ou achatados (Figura 17), com cerca de $1 \mathrm{~cm}$ de diâmetro, coloração amarela ou vermelha, forte aroma e alta pungência. Na culinária do estado de Goiás, é usada como tempero no preparo de carnes, arroz, feijão e biscoitos de polvilho. Depois de maduros, seus frutos são comercializados em conserva de salmoura, vinagre ou azeite. Sua picância atinge 50 mil unidades Scoville e 8 pontos na escala de temperatura (IBURG, 2005).

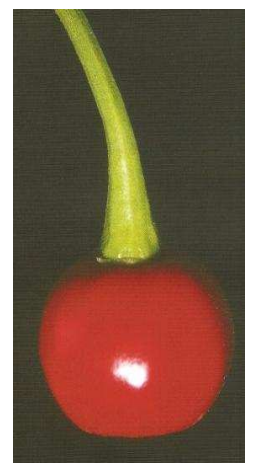

Figura 17. Foto de pimenta-de-bode ainda sem colher

\section{Pimenta-de-cheiro}

Muitas pimentas levam esse nome o que cria confusões no mundo das Capsicuns. Essa variedade em especial pode ser considerada como mais conhecida e popular da família. Costuma ser utilizada quando madura (cor amarela), e é particularmente apreciada nas regiões Norte, Cento-Oeste e Sudeste do Brasil. O tamanho dos frutos variam de 3 a $4 \mathrm{~cm}$ de comprimento e de 1 a 1,5 cm de largura (Figura 18). Sua pungência é mediana, situando-se 
entre 10 mil e 50 mil unidades de Scoville e variando de 6 a 8 pontos na escala de temperatura. Aromática e picante é largamente empregada no tempero de cozidos, ensopados e conservas (REIFSCHNEIDER, 2000).

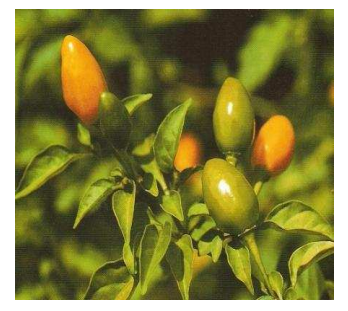

Figura 18. Foto de pimenta-de-cheiro ainda sem colher

\section{Pimenta-de-cheiro-do-Norte}

Muito apreciada pelo aroma forte e característico, a pimenta-de-cheiro-do-norte se subdivide em diversos tipos, com diferentes formatos, tamanhos e cores (Figura 19). Há frutos em tom amarelo-leitoso, outros de cor amarela mais forte, além de alaranjados, rosados, avermelhados e até pretos. Seu comprimento varia entre 1,5 e $4 \mathrm{~cm}$ e a largura de 1 a $3 \mathrm{~cm}$. As variedades cultivadas no Norte do Brasil são compridas e aromáticas, embora algumas apresentem pungência suave outras são altamente picantes. Em geral, é excelente para o preparo de arroz, saladas e pratos a base de peixe. No Brasil é cultivada nas regiões Norte, Nordeste e Centro-Oeste. Sua pungência varia de 1 mil a 30 mil unidades Scoville, ficando entre 3 e 7 pontos na escala de temperatura (NETO, 2004).

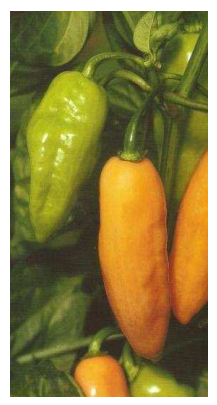

Figura 19. Foto de pimenta-de-cheiro-do-Norte ainda sem colher

\subsubsection{Capsicum frutescens}

A pimenta tabasco é a variedade mais conhecida dessa espécie, que reúne entre os seus frutos a pimenta malagueta, amplamente utilizada no Brasil, de onde é originária. Com frutos eretos, alongados, pequenos e de paredes finas suas plantas são do tipo arbustivo e apresentam vários caules (REIFSCHNEIDER, 2000). 


\section{Malagueta}

Uma das mais conhecidas e utilizadas no Brasil é muito cultivada na Zona da Mata mineira e no interior de São Paulo. Conforme a região produtora pode-se encontrar duas variáveis da mesma planta, as menores, chamadas de malaguetinha e as maiores denominadas malaguetão. Todas são idênticas nos quesitos de pungência e coloração. Antes de estarem maduros, seus frutos apresentam coloração verde. É nesse estágio que costumam ser consumidos em Minas Gerais. Depois, tornam-se vermelhos (Figura 20) e atingem entre 1,5 e $3 \mathrm{~cm}$ de comprimento e de 0,4 a $0,5 \mathrm{~cm}$ de largura. Na culinária, a pimenta malagueta é muito apreciada em pratos à base de peixes e carnes, além de estar presente em receitas típicas, como a do acarajé baiano. Em São Paulo, há uma preferência pela malagueta madura e vermelha. Muito utilizada e plantada na China e na Tailândia, a malagueta tem elevado grau de picância, atinge 9 pontos na escala de temperatura e entre 60 e 100 mil unidades Scoville. Em Portugal, o termo malagueta serve para designar um grande número de pimentas (REIFSCHNEIDER, 2000; NETO, 2004; IBURG, 2005).

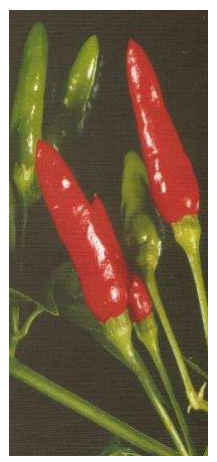

Figura 20. Foto de malagueta ainda sem colher

\section{Pimenta-de-passarinho}

Essa pimenta recebe esse apelido, porque quando seus frutos amadurecem, ganham uma tonalidade amarela chamando a atenção dos pássaros. Os frutos dessa variedade parecem pequenas azeitonas (Figura 21) com $1 \mathrm{~cm}$ de diâmetro. Sua pungência é mediana atingindo de 6 a 7 pontos na escala de temperatura e 20 mil unidades Scoville. A pimenta-de-passarinho é muito difundida no interior de São Paulo e na região central do Brasil. É utilizada em ensopados, sopas e molhos (BONTEMPO, 2007; NETO, 2004). 


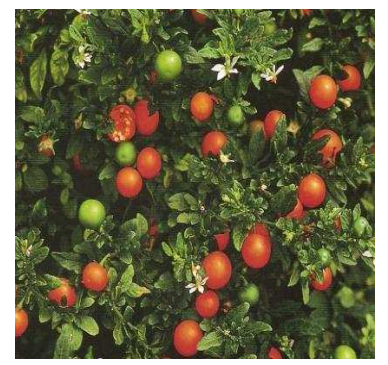

Figura 21. Foto de pimenta-de-passarinho ainda sem colher

\section{Tabasco}

Tabasco é o nome de uma pequena cidade mexicana. Pelo que se sabe, foi lá que se originou essa pimenta. Os frutos do tabasco são eretos (Figura 22) e tem cerca de $7 \mathrm{~cm}$ de comprimento e $1 \mathrm{~cm}$ de largura. Antes de amadurecerem, são amarelos, depois tornam-se alaranjados e finalmente vermelhos. Cada planta produz em média 100 frutos. Seu grau de pungência varia de 30 mil a 50 mil unidades Scoville, e 8 na escala de temperatura. Sua polpa é muito utilizada no preparo de peixes e quando frescas podem ser adicionadas a saladas. A pimenta tabasco no Brasil é mais encontrada no estado do Ceará (NETO, 2004).

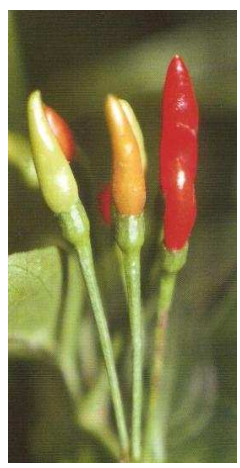

Figura 22. Foto de tabasco ainda sem colher

\subsubsection{Piperáceas}

A pimenta é uma velha conhecida dos europeus. O conde de Ficalho, anotador dos Colóquios de Garcia da Orta registrou em seus escritos que os árabes foram os responsáveis pela a introdução das pimentas no continente europeu durante a Idade Média. Eles levaram algumas espécies através do mar Vermelho e do Golfo Pérsico. Essas especiarias chegavam aos mercados com preços elevadíssimos (REIFSCHNEIDER, 2000).

\section{Cubeba (Pipper cubeba)}

Nativa da ilha de Java na Indonésia hoje é mais produzida em Serra Leoa e no Congo. Seus frutos, um pouco maiores do que os da pimenta-do-reino apresentam superfície rugosa 
(Figura 23) e ficam presos ao pé por uma pequena haste o que deu origem ao apelido pimentade-rabo. Picante e amarga, a cubeba tem forte aroma de madeira seca e só pode ser usada moída. Seu grau de pungência é de 3 na escala de temperatura (NETO, 2004).

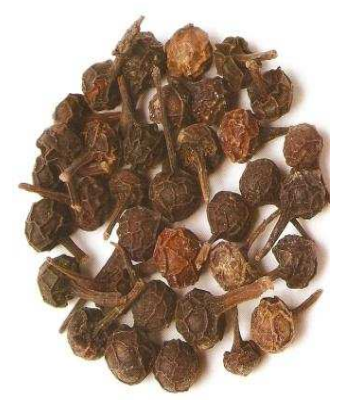

Figura 23. Foto de cubeba antes de moer

\section{Pimenta-do-reino Branca (Pipper nigrum)}

Originalmente os grãos de pimenta-do-reino são verdes, e para se tornarem brancos (Figura 24) precisam passar por um processo que consiste em ensacá-los e deixá-los imersos em água límpida e corrente. Após uma ou duas semanas, o prazo varia de acordo com o grau de maturação, as cascas ficam amolecidas e podem ser facilmente removidas. Estas são retiradas dos sacos, lavadas e secadas em fornos ou ao sol. A partir daí estão prontas para o consumo, seja em grãos ou moídas. Seu grau de pungência na escala de temperatura é 4 (IBURG, 2005; NETO, 2004).

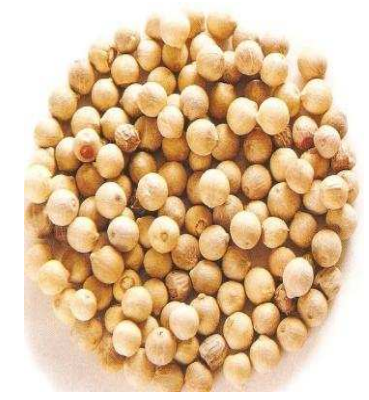

Figura 24. Foto de pimenta-do-reino branca em grãos

\section{Pimenta-do-reino Preta (Pipper nigrum)}

Seu preparo envolve a secagem das sementes em fornos ou ao sol. Ela é comercializada inteira (Figura 25) ou moída, e há muitas variações quanto aos diferentes graus de moagem. No Brasil é popular a versão mais fina. Seu grau de pungência é de 3 na escala de temperatura (NETO, 2004). 


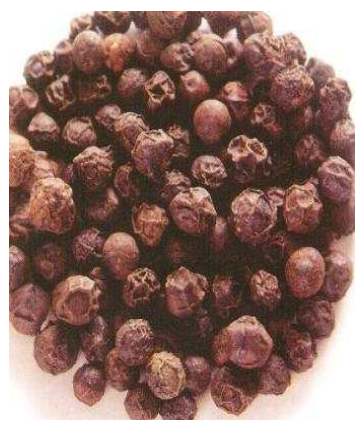

Figura 25. Foto de pimenta-do-reino preta em grãos

\section{Pimenta-do-reino Rosa (Pipper nigrum)}

A pimenta-do-reino rosa nada mais é do que o grão maduro da pimenta-do-reino. A cor avermelhada (Figura 26) que atinge nesta faze faz com que seja confundida com a semente de aroeira, mas o sabor e o aroma são bem diferentes. A pimenta-do-reino rosa é vendida seca ou em salmoura e marca presença na culinária Francesa e Brasileira. O Brasil é um dos seus maiores produtores. O grau de pungência é 2 na escala de temperatura (IBURG, 2005).

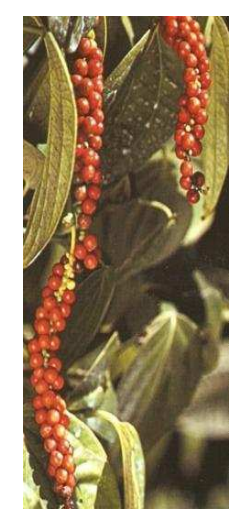

Figura 26. Foto de pimenta-do-reino rosa ainda sem colher

\section{Pimenta-do-reino Verde (Pipper nigrum)}

Sua cor verde (Figura 27) deve-se ao fato de os grãos serem mantidos em estado natural, sem passar por processos de secagem ou lavagem. Costumam ser mantidas em salmoura, mas também podem ser desidratas o que deixa com tamanho reduzido e casca rugosa. Seu grau de pungência é 2 na escala de temperatura (NETO, 2004). 


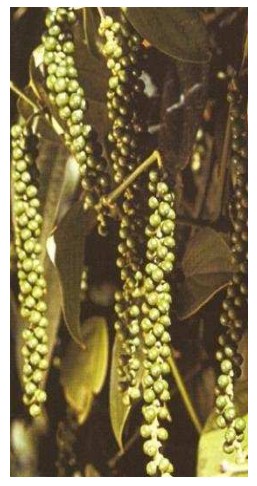

Figura 27. Foto de pimenta-do-reino verde ainda sem colher

\subsubsection{Falsas Pimentas}

Algumas sementes, bagas, frutos popularmente conhecidas como pimentas na verdade não pertencem nem a família das Piperáceas nem a dos Capsicum. Boa parte dessas "falsas pimentas" são extremamente importantes na culinária mundial (NETO, 2004).

\section{Jamaica (Pimenta dioica)}

Fortemente aromática, tem um sabor que mescla nuances de cravo-da-índia, canela e noz-moscada, acrescidas de uma ligeira picância. Seu formato lembra a pimenta-do-reino (Figura 28) e provavelmente foi por esse motivo que começou a ser chamada de pimenta. Seu grau de picância é 1 na escala de temperatura (BONTEMPO, 2007).

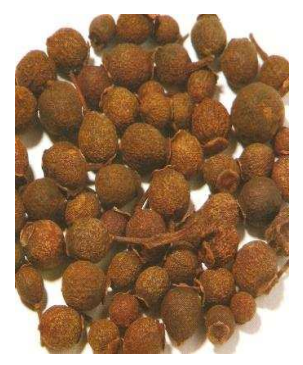

Figura 28. Foto de jamaica em grãos

\section{Pimenta-de-macaco (Xylopia aromatica)}

Trata-se de uma semente escura e rugosa, originária de uma árvore que pode atingir 6 m de altura. Também conhecida como pimenta-de-negro, pertence à família das anonáceas, sendo, portanto parente da pinha e da graviola (Figura 29). Nasce na região do cerrado brasileiro que abrange os estados de Minas Gerais, Goiás, Mato Grosso e parte de São Paulo. Apesar de bastante aromática e saborosa, ainda é pouco conhecida fora da culinária regional desses lugares. São usadas para condimentar carne. Sua melhor aplicação é como substituta da 
pimenta-do-reino. Seu grau de picância é 2 na escala de temperatura (BONTEMPO, 2007; NETO, 2004).

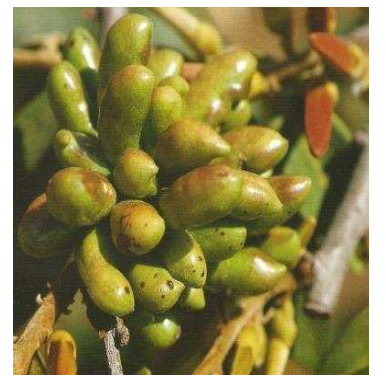

Figura 29. Foto de pimenta-de-macaco ainda sem colher

\section{Pimenta Rosa (Schinus terebinthifolius)}

Nativa da América do Sul é muito confundida com a pimenta-do-reino rosa, embora tenha aroma e sabor totalmente diferentes. Suas sementes são colhidas da aroeira. É muito utilizada em pratos a base de peixes, e com ornamento de alguns pratos devido a sua bela aparência (Figura 30). Na sua versão em pó, a pimenta rosa é conhecida pelo nome de Sancho. Presente em vários locais do Brasil, ocorre de Pernambuco ao Rio Grande do Sul em diversos tipos de vegetações, ela é exportada para a França, deu um toque tropical à nouvelle cuisine e foi por lá rebatizada poivre rose, retornando ao Brasil como produto importado. Seu grau de picância é zero (REIFSCHNEIDER, 2000; ORRICO, 2004).

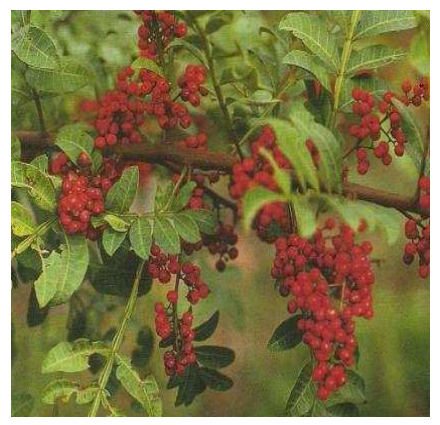

Figura 30. Foto de pimenta rosa ainda sem colher

\section{Pimenta Síria}

Trata-se de uma mistura de especiarias (Figura 31) que leva pimenta Jamaica, pimenta-do-reino preta, canela, cravo e noz-moscada. Tem sabor picante e pode ser usada no preparo de peixes assados e cozidos e em molhos em geral, além de ser um dos principais ingredientes do quibe e da esfirra árabes. Seu grau de picância é 2 na escala de temperatura (BONTEMPO, 2007). 


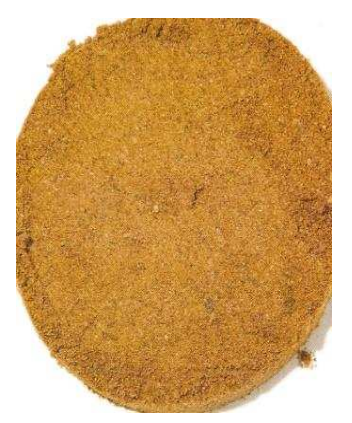

Figura 31. Foto de pimenta síria

\section{Pimenta-da-Tasmânia (Tasmannia lanceolata)}

Suas bagas secas lembram as da pimenta-do-reino preta (Figura 32). Porém a pimentada-tasmânia é pelo menos dez vezes mais picante do que a pimenta-do-reino. Inicialmente seu gosto é suave, mas logo adquire uma intensa pungência cítrica (NETO, 2004).

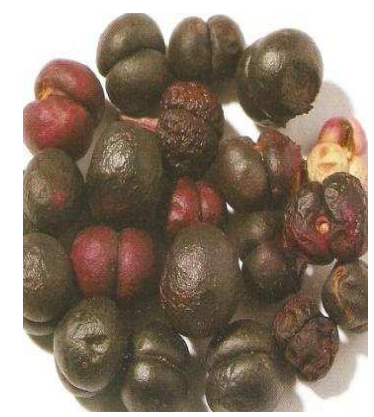

Figura 32. Foto de pimenta-da-Tasmânia em grãos

As pimentas (Figura 33) são também sinalizadoras das comidas regionais, premeditando ou até revelando os aromas e sabores típicos de cada região. O pimentão, a pimenta dedo-de-moça, a aroeira vermelha e a pimenta cambuci são as mais consumidas no Sul e Sudeste do Brasil (SILVA, 1996). A pimenta-de-cheiro se espalha pelo país, com características particulares em cada lugar: amarelas, vermelhas, alaranjadas, verdes, quase pretas, alongadas, arredondadas, triangulares, campanuladas, retangulares. A pimenta bode e a pimenta malagueta são as mais comuns no Nordeste. Na Bahia, as malaguetas verdes e vermelhas frescas temperadas em uma espécie de molho vinagrete acompanham os vatapás, as moquecas, os caranguejos, etc., mas os baianos também apreciam a pimenta curtida (tanto a malagueta quanto a de cheiro) e no preparo de molhos específicos, como o do acarajé, conhecido como Molho Nagô. No Norte, a pimenta-cheirosa, a murupi e a pimenta-de-cheiro do Pará são usadas frescas, curtidas de forma tradicional ou curtidas no tucupi, o líquido extraído da mandioca brava, com o qual são feitos os principais pratos amazônicos. No Centro-Oeste e no sertão nordestino e de Minas Gerais a pimenta-de-cheiro é bastante usada, 
inclusive fresca, na finalização de alguns pratos, como, por exemplo, a galinhada ou o capote com arroz (ORRICO, 2004).

\begin{tabular}{|c|c|c|c|c|}
\hline \multirow[b]{2}{*}{ Família } & \multirow[b]{2}{*}{ Espécie } & \multicolumn{2}{|c|}{ Grau de ardência } & \multirow[b]{2}{*}{ Utilização na culinária } \\
\hline & & Temperatura & Scoville & \\
\hline $\begin{array}{l}\text { Capsicum } \\
\text { annuum }\end{array}$ & Jalapeno & 5 & $2,5-5 \mathrm{mil}$ & Molhos \\
\hline $\begin{array}{l}\text { Capsicum } \\
\text { annuum }\end{array}$ & Mulata & $0-1$ & $100-500$ & Ornamentação e saladas \\
\hline $\begin{array}{l}\text { Capsicum } \\
\text { annuum }\end{array}$ & $\begin{array}{c}\text { Pimenta-de- } \\
\text { mesa }\end{array}$ & 3,5 & $2 \mathrm{mil}$ & Carnes, molhos e saladas \\
\hline $\begin{array}{l}\text { Capsicum } \\
\text { annuum }\end{array}$ & Pimentão & 0 & 0 & $\begin{array}{l}\text { Saladas, molhos refogados, } \\
\text { grelhados e recheados }\end{array}$ \\
\hline $\begin{array}{l}\text { Capsicum } \\
\text { annuum }\end{array}$ & Piquin & $8-9$ & $40-70 \mathrm{mil}$ & Sopas, lentilhas, feijão e ervilhas \\
\hline $\begin{array}{l}\text { Capsicum } \\
\text { baccatum }\end{array}$ & Cambuci & 0 & 0 & Saladas, cozidos e conservas \\
\hline $\begin{array}{l}\text { Capsicum } \\
\text { baccatum }\end{array}$ & $\begin{array}{c}\text { Cumari } \\
\text { verdadeira }\end{array}$ & 8 & $30-50 \mathrm{mil}$ & Molhos, cozidos e marinados \\
\hline $\begin{array}{l}\text { Capsicum } \\
\text { baccatum }\end{array}$ & $\begin{array}{l}\text { Dedo-de- } \\
\text { moça }\end{array}$ & $5-6$ & $5-15 \mathrm{mil}$ & Saladas, cozidos e feijão \\
\hline $\begin{array}{l}\text { Capsicum } \\
\text { baccatum }\end{array}$ & $\begin{array}{l}\text { Peito-de- } \\
\text { moça }\end{array}$ & $5-6$ & $10 \mathrm{mil}$ & Saladas, molhos, cozidos e feijão \\
\hline $\begin{array}{l}\text { Capsicum } \\
\text { baccatum }\end{array}$ & Pimenta fina & 8 & $30-50 \mathrm{mil}$ & Saladas, cozidos e feijão \\
\hline $\begin{array}{l}\text { Capsicum } \\
\text { baccatum }\end{array}$ & Pitanga & $5-6$ & $15-30 \mathrm{mil}$ & Caldos, ensopados e peixes \\
\hline $\begin{array}{l}\text { Capsicum } \\
\text { chinense }\end{array}$ & Cabacinha & 8 & $50 \mathrm{mil}$ & Molhos e saladas \\
\hline $\begin{array}{l}\text { Capsicum } \\
\text { chinense }\end{array}$ & $\begin{array}{l}\text { Chora- } \\
\text { menino }\end{array}$ & $7-8$ & $30-50 \mathrm{mil}$ & Saladas, peixes, caldos e sopas. \\
\hline $\begin{array}{l}\text { Capsicum } \\
\text { chinense }\end{array}$ & $\begin{array}{l}\text { Cumari-do- } \\
\text { Pará }\end{array}$ & 8 & $50 \mathrm{mil}$ & Conservas \\
\hline $\begin{array}{l}\text { Capsicum } \\
\text { chinense }\end{array}$ & Murupi & $8-9$ & $60 \mathrm{mil}$ & Molhos e conservas \\
\hline
\end{tabular}




\begin{tabular}{|c|c|c|c|c|}
\hline $\begin{array}{l}\text { Capsicum } \\
\text { chinense }\end{array}$ & $\begin{array}{c}\text { Pimenta de } \\
\text { biquinho }\end{array}$ & 1 & $1 \mathrm{mil}$ & Molho, peixes e carnes \\
\hline $\begin{array}{l}\text { Capsicum } \\
\text { chinense }\end{array}$ & $\begin{array}{l}\text { Pimenta-de- } \\
\text { bode }\end{array}$ & 8 & $50 \mathrm{mil}$ & Carnes, arroz, feijão e biscoitos \\
\hline $\begin{array}{l}\text { Capsicum } \\
\text { chinense }\end{array}$ & $\begin{array}{l}\text { Pimenta-de- } \\
\text { cheiro }\end{array}$ & $6-8$ & $10-50 \mathrm{mil}$ & Cozidos, ensopados e conservas \\
\hline $\begin{array}{l}\text { Capsicum } \\
\text { chinense }\end{array}$ & $\begin{array}{l}\text { Pimenta-de- } \\
\text { cheiro-do- } \\
\text { Norte }\end{array}$ & $3-7$ & $1-30 \mathrm{mil}$ & Arroz, saladas e peixes \\
\hline $\begin{array}{l}\text { Capsicum } \\
\text { frutescens }\end{array}$ & Malagueta & 9 & $60-100 \mathrm{mil}$ & Peixes, carnes e receitas típicas \\
\hline $\begin{array}{l}\text { Capsicum } \\
\text { frutescens }\end{array}$ & $\begin{array}{l}\text { Pimenta-de- } \\
\text { passarinho }\end{array}$ & $6-7$ & $20 \mathrm{mil}$ & Ensopados, sopas e molhos \\
\hline $\begin{array}{l}\text { Capsicum } \\
\text { frutescens }\end{array}$ & Tabasco & 8 & $30-50 \mathrm{mil}$ & Peixes e saladas \\
\hline Piperáceas & Cubeba & 3 & --- & Tempero \\
\hline Piperáceas & $\begin{array}{l}\text { Pimenta-do- } \\
\text { reino branca }\end{array}$ & 4 & --- & Tempero \\
\hline Piperáceas & $\begin{array}{l}\text { Pimenta-do- } \\
\text { reino preta }\end{array}$ & 3 & --- & Tempero \\
\hline Piperáceas & $\begin{array}{l}\text { Pimenta-do- } \\
\text { reino rosa }\end{array}$ & 2 & --- & Tempero e conservas \\
\hline Piperáceas & $\begin{array}{l}\text { Pimenta-do- } \\
\text { reino verde }\end{array}$ & 2 & --- & Tempero e conservas \\
\hline
\end{tabular}

Figura 33. Quadro resumo do grau de ardência e utilização na culinária das pimentas

\subsection{Composição das pimentas}

Embora existam muitas plantas picantes (gengibre, alho, aroeira), geralmente uma pimenta é assim caracterizada por possuir piperina (gênero Piper) ou a capsaicina (gênero Capsicum) em sua composição (BONTEMPO, 2007).

A capsaicina é um componente químico que estimula os termos receptores das mucosas e da pele, dependendo da quantidade do princípio ativo. Já á piperina tem ação cáustica direta, irritando a área de contato, produzindo efeitos vasodilatadores semelhantes à capsaicina, mas de modo quimicamente diferente (IBURG, 2005).

Foram identificados e isolados cinco componentes naturais da família das pimentas e um sintético, o qual é usado como medida de referência para determinar pungência relativa 
das outras. A capsaicina é o mais poderoso destes componentes, deve ser manipulado com extremo cuidado. Sua inalação não é tóxica, mas é irritante e perturbadora das vias aéreas e da pele (CARREIRO, 2006).

A capsaicina pura é um composto hidrofóbico, incolor, inodoro. Quimicamente a capsaicina é 8-metil-N-vanilil 1-6 nonamida, um agente irritante para os mamíferos, incluindo humanos, e produz uma forte sensação de queimação em qualquer tecido que entre em contato (BONTEMPO, 2007).

Além dos princípios ativos capsaicina e piperina, as pimentas são muito ricas em vitamina $\mathrm{A}, \mathrm{E}$ e $\mathrm{C}$, acido fólico, zinco e armazenam potássio, além de serem livres de colesterol. As pimentas também contêm bioflavonóides e pigmentos vegetais carotenóides como o licopeno. Existem mais de 600 diferentes carotenóides, dos quais 50 são utilizados pelo corpo humano, dentre eles destacam-se o alfa-caroteno, beta-caroteno, luteína, licopeno, zeaxantina e a criptoxantina. Dentre os carotenóides mais abundantes nos tecidos humanos encontram-se o betacaroteno e o licopeno. As pimentas vermelhas e amarelas são uma das fontes vegetais mais ricas em betacaroteno (ANJO, 2004).

\subsection{Os benefícios do uso da pimenta para saúde}

Segundo Hipócrates, o Pai da medicina, devemos fazer dos alimentos nossos remédios. Essa filosofia era a base de toda a medicina grega antiga e ensinava que a boa alimentação é o alicerce da saúde. Contudo, muito mais do que uma técnica alimentar, o sistema de Hipócrates utilizava o poder direto de cura de diversos alimentos, empregando-os tanto na recuperação do organismo nas diversas enfermidades, quanto na prevenção das mesmas (BONTEMPO, 2007).

Na lista dos alimentos-remédios da Grécia dentre vários alimentos estavam as pimentas. Concentravam a atenção no efeito especifico do alimento e, com base nele, dietas exclusivas ou concentradas em determinado item, eram prescritas para o tratamento de diversas doenças. Entendia-se que o corpo é formado pela essência dos alimentos ingeridos: se alimentos ruins ou prejudiciais eram ingeridos, poderiam provocar distúrbios e doenças classificadas pela medicina; em caso oposto, os bons alimentos eram considerados como capazes de curar aquilo que os maus produziram (CARREIRO, 2006).

Embora esta visão e experiência não figurem como essencial na medicina convencional moderna, as novas correntes de pensamento médico já a resgataram, tendo agora outra 
realidade quanto à importância da alimentação e do poder curativo de determinados alimentos.

Atualmente existe o conceito e a classificação de "alimentos funcionais", que de acordo com a American Dietectic Association (ADA) são definidos como qualquer substância ou componente de um alimento que proporciona benefícios para a saúde, inclusive a prevenção e o tratamento de doenças; porém a legislação para alimentos funcionais ainda é incipiente. Esses produtos podem variar de nutrientes isolados, produtos de biotecnologia, suplementos dietéticos, alimentos geneticamente construídos até alimentos processados e derivados de plantas, como por exemplo, a capsaicina ingrediente ativo das pimentas. Com o advento da medicina ortomolecular, tem-se uma rendição atualizada do pensamento de Hipócrates, pois a ciência já conhece as propriedades medicinais e composições que explicam como os alimentos podem curar (ANJO, 2004).

Segundo a Agência Nacional de Vigilância Sanitária (www.anvisa.gov.br), propriedade funcional é aquela relativa ao papel metabólico ou fisiológico que o nutriente ou não nutriente tem no crescimento, desenvolvimento, manutenção e outras funções normais do organismo humano.

De acordo com a homeopatia, ou com o princípio homeopático de que "os semelhantes curam-se pelos semelhantes", uma substância capaz de produzir determinado sintoma em um indivíduo tem também a capacidade de curar essa alteração em uma condição de doença, quando ministradas em doses pequenas. Assim, substâncias como a pimenta, podem ser excelentes medicamentos (REIFSCHNEIDER, 2000).

$\mathrm{Na}$ alopatia, a oleorresina de Capsicum tem sido usada na fabricação de creme analgésico para aliviar dores musculares e distúrbios articulares. A capsaicina torna a pele sensível depois do ardor. Contudo altas doses de drogas que contenham componentes concentrados de pimenta, se administradas por longos períodos, podem causar gastrite crônica, agressão ao fígado e aos rins e efeitos neurotóxicos. Isso ocorre devido ao fato de que essas drogas apresentam concentrações elevadas de capsaicina ou piperina, não acontecendo o mesmo com a pimenta in natura, a não ser que sejam ingeridas em quantidades absurdas e por longo tempo (BONTEMPO, 2007).

Por ser antioxidante rica em flavonóides e em vitamina $\mathrm{C}$, a pimenta pode ainda reduzir o risco de doenças crônicas como câncer de próstata, catarata e diabetes, também pelo seu efeito desintoxicante do sangue. Como alimento, ela impede a coagulação do sangue e pode ser também uma forma importante de evitar doenças como trombose (LUNN, 2007). 
Pesquisas dos últimos dez anos têm demonstrado que a capsacina, princípio ativo das pimentas do gênero Capsicum, apresenta propriedades medicinais comprovadas: atuando então como cicatrizante de feridas, antioxidante, agindo na dissolução de coágulos sanguíneos, previnindo a arteriosclerose, controlando o colesterol, evitando hemorragias e aumentando a resistência física (KASBIA, 2005; ADAMS, 2007).

Foi constatado também que a capsaicina atua sobre as membranas mucosas, tanto bucais quanto gástricas, o que parece ser uma contradição ao conceito popular de que as pimentas causam úlceras. Tornando o conceito sem fundamentação. No entanto, aqueles que já possuem úlceras, gastrites, hemorróidas e diverticulites podem piorá-las com o uso da pimenta (REIFSCHNEIDER, 2000).

Alguns cientistas apontam que o consumo regular de pimenta do gênero Capsicum provou ser útil em muitas condições alteradas, como no diabetes, câncer e artrites. As pesquisas mostram que não somente seu consumo regular ajuda melhorar o controle de níveis de insulina, mas pode também ajudar a combater o processo inflamatório responsável pela artrite, mas não foi relatado a quantidade e o tipo de pimenta a ser utilizada (AHUJA, 2006).

Investigadores da Universidade da Tasmânia (Austrália) em 2002 relataram uma experimentação mostrando que o consumo regular de pimentão numa refeição, ajudou a controlar o equilíbrio da insulina em $60 \%$ do grupo estudado, numa pesquisa randomizada cruzada. Foram realizadas amostras de sangue para verificação dos níveis de glicose, da insulina e do peptídeo $\mathrm{C}$ do soro. Os resultados apontam uma redução dos níveis de glicose, estabilidade da insulina e uma menor secreção de peptídeo C (cuja elevação altera os níveis de glicose e de insulina) (AHUJA, 2006).

Foi verificado também que o uso regular de pimenta influencia a liberação de endorfinas, mediadores químicos cerebrais responsáveis pela sensação de bem estar e pela variação do bom humor, estimulando também o sistema nervoso simpático produzindo aumento da liberação de catecolaminas com conseqüente a diminuição do apetite e ingestão de calorias. Isso mostra que a pimenta pode ser útil em programas de controle de peso corporal (KASBIA, 2005; ADAMS, 2007).

A Nutróloga e especialista em medicina ortomolecular Tâmara Mazaracki, afirma que a capsaicina é capaz de reduzir a formação de gases e melhorar a produção do suco gástrico, afirma também que a pimenta parece ser capaz de combater a bactéria Helicobacter pylori envolvida na formação de gastrites e úlceras estomacais (BONTEMPO, 2007) 


\section{CONCLUSÃO}

Como pode-se verificar, os estudos relacionados à pimenta começaram muito antes do que se imagina, as suas propriedades despertam interesse em muitos tipos de atividades, tendo como exemplo a área de saúde, culinária, agronegócios, e até mesmo na área militar (agentes lacrimogêneos com base no extrato natural de pimenta).

Com tantas influências na culinária nacional, a pimenta surgiu como um ingrediente que identifica os pratos regionais, sendo extremamente importante para a preservação das características de determinadas preparações e conseqüentemente preservando as culturas alimentares locais

A pimenta é classificada como alimento funcional por alguns estudiosos, ou seja, além dos seus nutrientes, possui componentes que promovem e preservam a saúde. As pimentas também são utilizadas como matéria-prima para diversos medicamentos orais e locais, como emplastros que aliviam dores musculares, no tratamento de desordens gastrintestinais, na prevenção de arteriosclerose, acidente vascular cerebral, doenças cardíacas, entre outras.

Enfim, são muitos assuntos e estudos que retratam a utilização das pimentas e os possíveis benefícios que o uso destas traz ao organismo, porém nenhum estudo é o bastante conclusivo, não descrevendo a dose a ser utilizada ou o tipo específico da pimenta para cada patologia estudada, o que limita o conhecimento e a própria prescrição de seu uso, tornando esse assunto propício a novas pesquisas mais específicas e descritivas. 


\section{REFERÊNCIAS BIBLIOGRÁFICAS}

ADAMS, B. D. Antioxidant, anti-inflammatory, and antimicrobial properties of garlic and onions. Nutrition \& Food Science. v. 37 n. 3, p. 178-183, 2007

AHUJA, K. D. Effects of chili consumption on postprandial glucose, insulin, and energy metabolism. J Clin Nutr. n .84, p.63-9, 2006.

ANJO, D.F. Alimentos funcionais em angiologia e cirurgia vascular. Jornal Vascular Brasileiro. Santa Catarina, v. 3, n. 2, p. 145-154. 2004.

BONTEMPO, M. Pimenta e seus benefícios. São Paulo: Alaúde, 2007.

CARREIRO, D. M. Entendendo a importância do processo alimentar. São Paulo: Referência Ltda, 2006.

CASCUDO, L.C. História da alimentação no Brasil. São Paulo: Itatiaia, 1983.

FILHO, D.F; OLIVEIRA, M.C; MARTINS, L.H. Diversidade fenotípica em pimenteiras cultivadas na Amazônia. Amazônia, 2000.

GARCIA, J.; KAMADA,T.; JACOBSON,T.K. Superação de dormência em sementes de pimenta-do-reino. Pesquisa Agropecuária Tropical., São Paulo, v. 30, n. 2, p. 51-54, jul./dez. 2000.

IBURG, A. Especiarias de A-Z. São Paulo: Lisma, 2005.

KASBIA, S. G. Functional foods and nutraceuticals in the management of obesity. Nutrition \& Food Science. V. 35, n. 5, p. 344-352, 2005. 
LUNN, J. Nutrição e envelhecimento saudável. Nutrição em Pauta. São Paulo, ano 15, v. 85, p. 5-9, jul/ago 2007.

NETO, N.L. Dicionário Gastronômico: Pimentas com suas receitas. São Paulo: Boccato, 2004.

ORRICO, O. Molhos, picantes e pimentas. Jangada Brasil. Pará, maio 2004.

REIFSCHNEIDER, F.J.B. Capsicum: pimentas e pimentões no Brasil. Brasília: EMBRAPA, 2000. 113p.

SILVA, S.; TASSARA,H. Frutas no Brasil. São Paulo: Empresa das artes, 1996.

STADEN, H. Duas viagens ao Brasil. São Paulo: Ed. da Universidade de São Paulo, 1974. $218 \mathrm{p}$. 